Check for updates

Cite this: RSC Adv., 2019, 9, 28704

Received 15th July 2019

Accepted 5th September 2019

DOI: $10.1039 / c 9 r a 05425 a$

rsc.li/rsc-advances

\section{A low molecular weight OLED material: 2-(4-((2- hydroxyethyl)(methyl)amino)benzylidene) malononitrile. Synthesis, crystal structure, thin film morphology, spectroscopic characterization and DFT calculations $\uparrow$}

\author{
M. Judith Percino, (iD *a Margarita Cerón, ${ }^{a}$ Perumal Venkatesan, (DD a Enrique Pérez- \\ Gutiérrez, (D) ${ }^{a}$ Pilar Santos, ${ }^{a}$ Paulina Ceballos, ${ }^{a}$ Armando E. Castillo, ${ }^{a}$ Paola Gordillo- \\ Guerra, ${ }^{a}$ Karnambaram Anandhan, (D) ${ }^{a}$ Oracio Barbosa-Garcia, ${ }^{b}$ Wilson Bernal ${ }^{b}$ \\ and Subbiah Thamotharan ${ }^{\mathrm{c}}$
}

2-(4-((2-Hydroxyethyl)(methyl)amino)benzylidene)malononitrile (HEMABM) was synthesized from 4[hydroxymethyl(methyl)amino]benzaldehyde and propanedinitrile to obtain a low molecular weight fluorescent material with an efficient solid-state emission and electroluminescence properties comparable to the well-known poly(2-methoxy-5(2'-ethyl)hexoxyphenylenevinylene) (MEH-PPV). The HEMABM was used to prepare an organic light-emitting diode by a solution process. Despite the title compound being a small molecule, it showed optical properties and notable capacity to form a film with smooth morphology $(10.81 \mathrm{~nm})$ closer to that of polymer MEH-PPV $(10.63 \mathrm{~nm})$. The preparation of the device was by spin coating, the electrical properties such as threshold voltage were about $1.0 \mathrm{~V}$ for both HEMABM and MEH-PPV, and the luminance $1300 \mathrm{~cd} \mathrm{~m}^{-2}$ for HEMABM and $2600 \mathrm{~cd} \mathrm{~m}^{-2}$ for MEH-PPV. This low molecular weight compound was characterized by SCXRD, IR, NMR, and El. Besides a quantitative analysis of the intermolecular interactions by PIXEL, density functional theory (DFT) calculations are reported.

\section{Introduction}

The utilization of soluble conjugate polymers as active materials in optoelectronic applications has opened the possibility of fabricating many different devices. Soluble conjugated polymers, with their advantages of low cost, flexibility, and high absorption coefficient, have shown a possibility for photodetection and photovoltaic applications..$^{1-5}$ In the past few years, poly(2-methoxy-5(2'-ethyl)hexoxy phenylenevinylene) (MEHPPV) has been considered as one of the most useful conducting polymers for various optoelectronic applications, such as sensors, organic solar cells, and organic light emitting diodes (OLED) because of its environmental stability, easy conductivity properties and processable deposition. ${ }^{6,7}$ The MEH-PPV acts as

${ }^{a}$ Unidad de Polímeros y Electrónica Orgánica, ICUAP, Benemérita Universidad Autónoma de Puebla, Val 3-Ecocampus Valsequillo, Independencia O2 Sur 50, San Pedro Zacachimalpa, Pue., Mexico, 7296. E-mail: judith.percino@correo.buap.mx

${ }^{b}$ Centro de Investigaciones en Óptica A. P. 1-948, 37150, León, Guanajuato, Mexico 'Biomolecular Crystallography Laboratory, Department of Bioinformatics, School of Chemical and Biotechnology, SASTRA Deemed University, Thanjavur 613 401, India $\dagger$ Electronic supplementary information (ESI) available. CCDC 1868089. For ESI and crystallographic data in CIF or other electronic format see DOI: 10.1039/c9ra05425a an electron donor (p-type semiconducting polymer) with a relatively low conductivity due to its low hole and electron mobilities when compared to inorganic semiconductor materials. ${ }^{\mathbf{8}, 9}$

Soluble organic semiconductors for OLEDs have received important attention since they offer a potential for the production by solution processing techniques such as spincoating, ink-jet printing or drop casting. ${ }^{10,11}$ Within this, the conjugated organic polymers have been generally considered as a suitable material for these techniques because of their good film forming capacity. ${ }^{12,13}$ In recent research, the numerous organic electroluminescent (EL) materials including polymers has focused on solution processable of small molecules which possess advantages of having well-defined structures and being uniformly reproducible. ${ }^{14,15}$ The parameters for the manufacture conditions such as the dye device, quantum yield, solvent or vacuum deposition, size of the films, etc. are very important to design a new compound with adequate optical properties and to understand structure-properties relationships. ${ }^{16,17}$ In this manner, synthesis of molecules with a substituent that interacted with the solvents, it's able to form films might be a valuable approach to solution processed OLEDs. ${ }^{18,19}$ The extended conjugated structures of well-defined small molecules involving alkyl and alkoxyl chains $\mathrm{s}^{15,20,21}$ may provide better solubility and 
higher glass thermal stability while maintaining high purity and reliable molecular structure-property correlations. ${ }^{22}$

On the other hand, the molecular orientation of organic semiconductors play an important role on small-molecule light-emitting diodes (OLEDs), i.e. the films morphology. Molecular orientation at the microscopic level can be reached in vacuum-deposited amorphous films or in spin coating for a better device performance. ${ }^{\mathbf{2 3 2 4}}$ Thin films based on organic small-molecule consist of single units, and each one has specific characteristics, such as geometric and electronic structures, as well as absorption and emission spectra. Therefore, the properties as solids came from of single molecule before fabricating the thin films or crystals. This means that the properties are shifted or changed depending on intermolecular interactions they form. Also, it is interesting that although most chemical phenomena take place in solution, the solvent is usually thought of as a spectator, acting merely as a medium to hold the reactants and allow them to encounter each other by diffusion. ${ }^{25}$ It well known cases as solvated electrons ${ }^{26}$ and the charge transfer to solvent transitions ${ }^{27}$ of simple anions, the solvent creates the electronic states that are of importance, primarily because the electrons of interest are not otherwise bound without the stabilizing presence of the solvent. Moreover, in electron transfer and related reactions, reorganization of the surrounding solvent molecules is the driving force to move the electron from the donor to the acceptor, and thus determines the reaction rate. ${ }^{28-30}$ Dielectric effects from collective solvent motions can lead to solvatochromic shifts in the electronic absorption spectra of solutes, ${ }^{31,32}$ and solvent molecules can provide viscous drag that changes the dynamics and thus the branching ratios of unimolecular isomerization reactions. ${ }^{33}$

Recently, the thin-film assemblies, most of which are amorphous in nature, are easily broken up by trying to deposit electron transporting layer (ETL), because small molecules are typically attached to each other only by weak intermolecular forces such as van der Waals, H-bonding and $\pi$ stacking interactions. Consequently, the highest reported efficiency of solution-processed small molecule OLEDs still relies on a vacuum-evaporated films, which is not practical for low-cost mass production of scalable devices. The solution process of small molecules encounters major difficulties to fabricate multilayers architectures because of redissolution of underlying layers. This problem can be avoided using orthogonal solvents, ${ }^{34,35}$ or by cross-linkable the organic functional materials $^{36,37}$ or designing a compound that showing a highly efficient solution-processed small-molecule for OLEDs.

Alternatively, cyano-substituted pyridine derivatives have been reported as electron-transporting (ET) properties and have been used in OLED devices showing acceptable efficiency. ${ }^{38,39}$ Herein, malononitrile based HEMABM derivative (Fig. 1) was developed by introducing two electronwithdrawing cyano-group substituents on the HEMAB. Emphasis is in comparing with the commercial polymer MEH-PPV, because it exhibits a long-conjugated system contrary to the title molecule, but the optical properties are very similar.
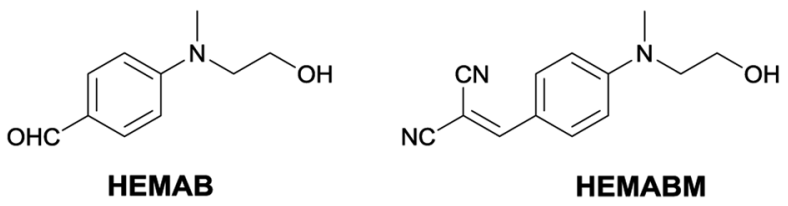

Fig. 1 Structure of the HEMAB and HEMABM.

In this study, it was prepared a small molecular weight compound with orange emission and it can be deposited as thin film by solution process. Their optical and luminance properties are compared with MEH-PPV. The electroluminescent behavior of the emitting material was studied in devices showing a wide spectral to orange. We focused on the study on the effect of the morphology development of solution processed OLEDs and to evaluate the manufacturing related to physical properties. The solvent study with 2-(4-((2-hydroxyethyl)(methyl) amino)benzylidene)malononitrile (HEMABM) was carried out before fabrication of OLED, for which we have chosen different polarities solvents such as $\mathrm{MeOH}$, isopropyl alcohol (IPA), ethyl acetate (EtOAc), THF, chlorobenzene (Ph-Cl), $\mathrm{CHCl}_{3}$, 1,4dioxane and toluene. It was investigated the morphological and photophysical properties of the solution-processed films by atomic force microscopy (AFM), and the electrical and electrooptical properties of solution-processed, as well as their current-voltage-luminance characteristics are reported. Finally, to identify the origin of optical properties, electronic structure calculations were performed. Further, the intermolecular interactions existing in the crystal structures and their energies were quantified for various dimers by PIXEL and DFT approaches in order to correlate with the intermolecular interaction that play role in solution and in the films.

\section{Result and discussion}

The HEMABM was obtained by a green synthetic methodology from the 4-((2-hydroxyethyl)(methyl)-amino)benzaldehyde HEMAB with good yield and the corresponding scheme and characterization are shown in $\mathrm{ESI}_{\dagger}^{\mathbf{4 0}}$ (Fig. 1).

Table 1 Absorbance values of HEMABM in different solvents at different concentrations ${ }^{a}$

\begin{tabular}{lccccc}
\hline \multicolumn{7}{l}{ Solvents } & & \multicolumn{5}{l}{ Absorbance (a.u.) } & & & \\
\cline { 3 - 6 } Solution & {$[\mathrm{M} 1]$} & {$[\mathrm{M} 2]$} & {$[\mathrm{M} 3]$} & {$[\mathrm{M} 4]$} & {$[\mathrm{M} 5]$} \\
\hline MeOH & 1.686 & 0.851 & 0.434 & 0.210 & - \\
IPA & 2.672 & 1.339 & 0.694 & 0.364 & 0.181 \\
EtOAc & 3.370 & 1.711 & 0.888 & 0.465 & 0.240 \\
THF & 3.198 & 1.614 & 0.832 & 0.433 & 0.216 \\
Ph-Cl & 3.332 & 1.693 & 0.854 & 0.427 & 0.219 \\
CHCl & 3.344 & 1.652 & 0.899 & 0.584 & 0.336 \\
1,4-Dioxane & 2.865 & 1.424 & 0.731 & 0.359 & 0.179 \\
Toluene & 4.616 & 2.302 & 1.166 & 0.600 & 0.304 \\
a $[\mathrm{M} 1]=5.5 \times 10^{-5} \mathrm{M} ;[\mathrm{M} 2]=2.75 \times 10^{-5} \mathrm{M} ;[\mathrm{M} 3]=1.38 \times 10^{-5} \mathrm{M} ;$ \\
{$[\mathrm{M} 4]=0.69 \times 10^{-5} \mathrm{M} ;[\mathrm{M} 5]=0.34 \times 10^{-5} \mathrm{M}$.} & &
\end{tabular}




\subsection{Optical properties of HEMABM in different media}

The UV-vis absorption spectra of HEMABM was recorded in different solvents with various polarity (polar aprotic, polar protic and non-polar) at different concentration $\left(5.50 \times 10^{-5}\right.$, $2.75 \times 10^{-5}, 1.38 \times 10^{-5}, 0.69 \times 10^{-5}$ and $\left.0.34 \times 10^{-5} \mathrm{M}\right)$, in order to find the best solvent to form films with acceptable morphologies for OLED. ${ }^{41}$ The absorbance intensity (molar absorption coefficient) showed a tendency to increase as the polarity decreases, except for ethyl acetate (EtOAc) and 1,4dioxane (polar aprotic), which indicating that the solute-solvent interaction is affected, Table 1 and Fig. 2. The absorption maxima $\lambda_{\max }$, were found in $427-430 \mathrm{~nm}$ range, but a smaller absorption band emerged below of $300 \mathrm{~nm}$, whose intensity increased with decreasing the concentration. The lowest absorbance intensity was for methanol < isopropyl alcohol (IPA) $\cong 1$,4-dioxane $<\mathrm{THF}<$ chlorobenzene $(\mathrm{Ph}-\mathrm{Cl})<\mathrm{CHCl}_{3}<$ EtOAc $<$ toluene, but the spectra shape did not change with THF, chlorobenzene, $\mathrm{CHCl}_{3}$, toluene. It is noted that the shoulder band intensity is increased with decreasing the concentration of solution in EtOAc, 1,4-dioxane and IPA Fig. 3(a and b).
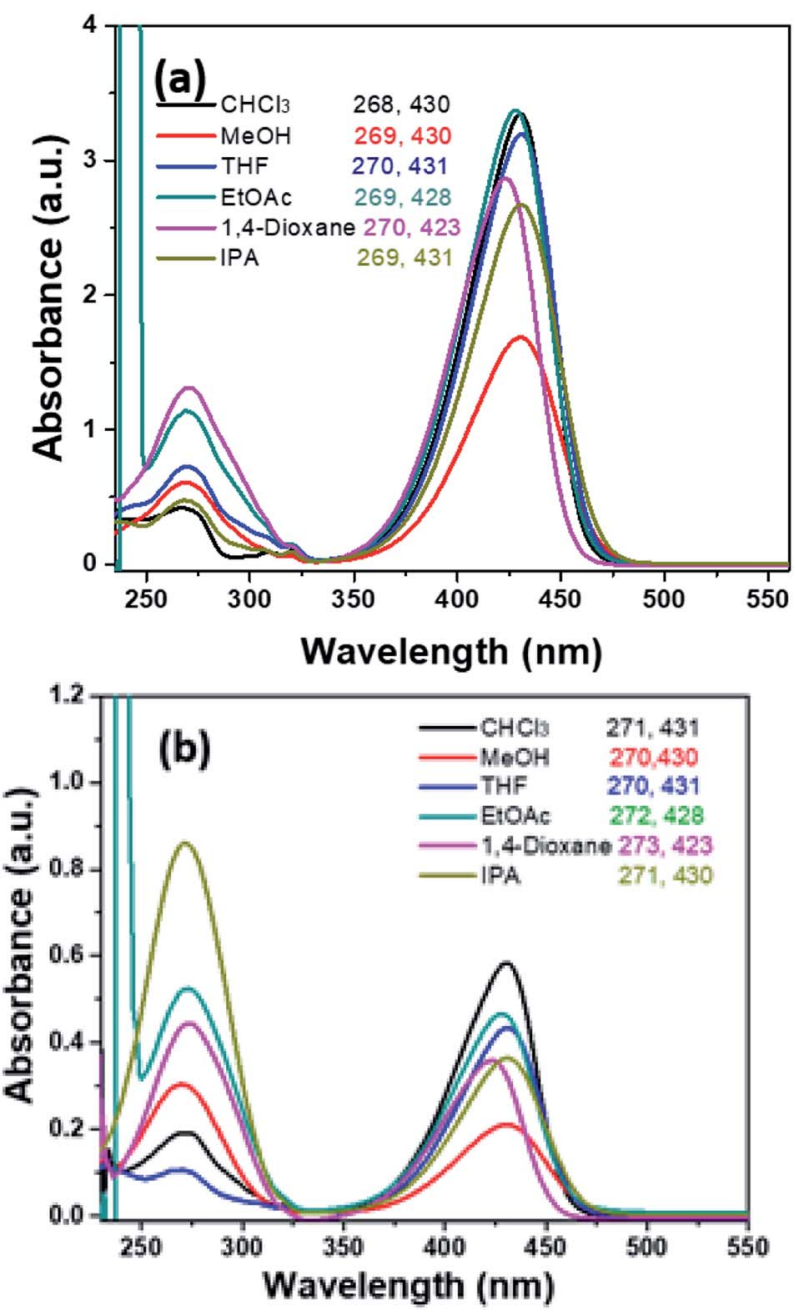

Fig. 2 The absorption spectra of HEMABM in different solvents with two different concentrations of solution (a) $5.50 \times 10^{-5} \mathrm{M}$ and solution (b) $0.69 \times 10^{-5} \mathrm{M}$.

\subsection{Theoretical calculation on absorption properties}

The electronic transitions of HEMABM were computed by TDDFT method in gas phase, and in solution state (MeOH, IPA, EtOAc, THF, Ph-Cl, $\mathrm{CHCl}_{3}$, 1,4-dioxane and toluene) with PBEPBE/6-311++G (d, p) level of theory. The calculated absorption wavelength $\left(\lambda_{\text {abs }}\right)$, oscillator strengths $(f)$, and major orbital transitions (in\%) for HEMABM are shown Table 2. The most important frontier molecular orbital (Highest Occupied Molecular Orbital) and LUMO (Lowest Unoccupied Molecular Orbital) transitions are presented in the Fig. 4.

From Table 2 , the computed $\lambda_{\max }$ absorption found at $410 \mathrm{~nm}$ in the gas phase and in the range of $439-449 \mathrm{~nm}$ in different solvents which belongs to the $\mathrm{H} \rightarrow \mathrm{L}$ transition. The second absorption is found at $327 \mathrm{~nm}$ in gas and $339-349 \mathrm{~nm}$ in solvents which belongs to $\mathrm{H}-1 \rightarrow \mathrm{L}$ and $\mathrm{H}-3 \rightarrow \mathrm{L}$ transitions. Additionally, another weak absorption is found in the range of 290-300 nm in gas and solvents which belongs to $\mathrm{H}-3 \rightarrow \mathrm{L}$ and $\mathrm{H}-1 \rightarrow \mathrm{L}$ transitions. The earlier intense $(\mathrm{H} \rightarrow \mathrm{L})$ transition is might be due to the intermolecular charge transfer transition and the latter two absorptions belong to $\pi \rightarrow \pi^{*}$ and $n \rightarrow \pi^{*}$ transitions, respectively.
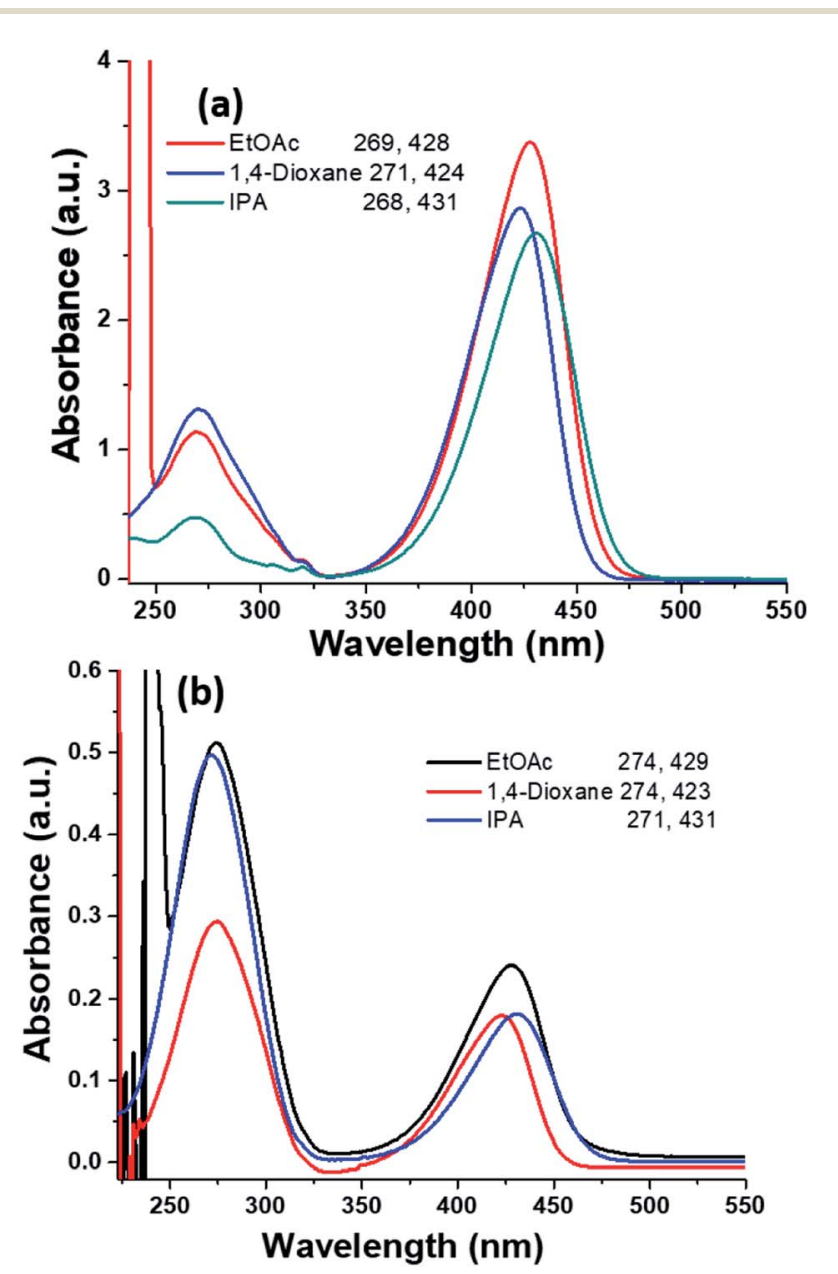

Fig. 3 The selected absorption spectrum of HEMABM in two different concentrations of solution (a) $5.50 \times 10^{-5} \mathrm{M}$ and solution (b) $0.34 \times$ $10^{-5} \mathrm{M}$ in different solvents. 
From the experimental, we found two absorption bands, the $\lambda_{\max }$ in the range of 430-427 $\mathrm{nm}$ and a smaller absorption band emerged below $300 \mathrm{~nm}$ as mentioned earlier. Experimental $\lambda_{\max }$ is may be due to CT and $\pi \rightarrow \pi^{*}$ transitions and latter smaller absorption belongs to $\mathrm{n} \rightarrow \pi^{*}$ transitions, respectively. Because the absorption intensity for $\lambda_{\max }$ (in experimental) is decreased as decreasing the concentrations of solution (Fig. 2) as described earlier. Further, to understand CT transition between the molecules, we carried out the NBO analysis for most stabilized dimer (D1) which formed by the strong $\mathrm{O}-\mathrm{H} \cdots \mathrm{N}$ intermolecular interaction. Crystallography information and the intermolecular interactions in crystal structure of HEMABM is depicted in the next section. The NBO analysis suggested that the charge transfer occur between the lone pair electron of N2 atom and the antibonding orbital of $\mathrm{O} 1-\mathrm{H} 1(\mathrm{O})$ bond and it is stabilized with $6 \mathrm{kcal} \mathrm{mol}^{-1}$.

The energy gap $\left(\Delta E_{(\mathrm{L}-\mathrm{H})}\right)$ is nearly the same in most of the solvents (2.02-2.07 eV) except the 1,4-dioxane and toluene (2.11 $\mathrm{eV}$ ), see Table 3. It is interesting to note that the HOMO-LUMO energy level of HEMABM is very closer to the HOMO-LUMO of MEH-PPV $(\mathrm{HOMO}=5.3 \mathrm{eV}, \mathrm{LUMO}=3.0 \mathrm{eV}) .{ }^{42}$ But, the $\Delta E_{(\mathrm{L}-\mathrm{H})}$ value for MEH-PPV is slightly higher than the HEMABM. This difference is mainly arising from the energy levels of LUMO orbital in HEMABM (Table 3). We observed that the $\Delta E_{(\mathrm{L}-\mathrm{H})}$ value is increased with decreasing the polarity of the solvent except $\mathrm{CHCl}_{3}$.

Briefly, the least $\Delta E_{(\mathrm{L}-\mathrm{H})}$ value obtained in methanol $(2.02 \mathrm{eV})$ and highest value obtained in toluene and 1,4-dioxane $(2.11 \mathrm{eV})$.

Table 2 Experimental $\lambda_{\exp }(\mathrm{nm})$ and computed $\lambda_{\text {abs }}(\mathrm{nm})$ for HEMABM with PBEPBE/6-311++G (d, p) level of theory

\begin{tabular}{|c|c|c|c|c|}
\hline$\lambda_{\mathrm{abs}}(\mathrm{DFT})$ & $\mathrm{eV}$ & $f$ & Major transition (\%) & $\lambda_{\exp }$ \\
\hline \multicolumn{5}{|l|}{ Gas } \\
\hline 410 & 3.02 & 0.6718 & $\mathrm{H} \rightarrow \mathrm{L}(93)$ & - \\
\hline 327 & 3.79 & 0.0921 & $\mathrm{H}-1 \rightarrow \mathrm{L}(51) ; \mathrm{H}-3 \rightarrow \mathrm{L}(35)$ & - \\
\hline 292 & 4.25 & 0.0594 & $\mathrm{H} \rightarrow \mathrm{L}+2(48) ; \mathrm{H}-3 \rightarrow \mathrm{L}(31) ; \mathrm{H}-1 \rightarrow \mathrm{L}(15)$ & - \\
\hline \multicolumn{5}{|l|}{ Methanol } \\
\hline 445 & 2.78 & 0.8412 & $\mathrm{H} \rightarrow \mathrm{L}(95)$ & 430 \\
\hline 352 & 3.52 & 0.1343 & $\mathrm{H}-1 \rightarrow \mathrm{L}(77) ; \mathrm{H}-3 \rightarrow \mathrm{L}(17)$ & \\
\hline 295 & 4.19 & 0.0876 & $\mathrm{H}-3 \rightarrow \mathrm{L}(70) ; \mathrm{H}-1 \rightarrow \mathrm{L}(14)$ & 269 \\
\hline \multicolumn{5}{|c|}{ Isopropyl alcohol } \\
\hline 447 & 2.78 & 0.8555 & $\mathrm{H} \rightarrow \mathrm{L}(96)$ & 431 \\
\hline 352 & 3.53 & 0.1314 & $\mathrm{H}-1 \rightarrow \mathrm{L}(77) ; \mathrm{H}-3 \rightarrow \mathrm{L}(18)$ & \\
\hline 296 & 4.19 & 0.0872 & $\mathrm{H}-3 \rightarrow \mathrm{L}(70) ; \mathrm{H}-1 \rightarrow \mathrm{L}(14)$ & 268 \\
\hline \multicolumn{5}{|c|}{ Ethyl acetate } \\
\hline 443 & 2.80 & 0.8499 & $\mathrm{H} \rightarrow \mathrm{L}(96)$ & 428 \\
\hline 347 & 3.57 & 0.1257 & $\mathrm{H}-1 \rightarrow \mathrm{L}(74) ; \mathrm{H}-3 \rightarrow \mathrm{L}(21)$ & \\
\hline 295 & 4.20 & 0.0914 & $\mathrm{H}-3 \rightarrow \mathrm{L}(67) ; \mathrm{H}-1 \rightarrow \mathrm{L}(17)$ & 269 \\
\hline \multicolumn{5}{|l|}{ THF } \\
\hline 445 & 2.78 & 0.8600 & $\mathrm{H} \rightarrow \mathrm{L}(96)$ & 430 \\
\hline 349 & 4.61 & 0.1110 & $\mathrm{H}-1 \rightarrow \mathrm{L}(75) ; \mathrm{H}-3 \rightarrow \mathrm{L}(20)$ & \\
\hline 295 & 4.20 & 0.0895 & $\mathrm{H}-3 \rightarrow \mathrm{L}(68) ; \mathrm{H}-1 \rightarrow \mathrm{L}(18)$ & 270 \\
\hline \multicolumn{5}{|c|}{ Chlorobenzene } \\
\hline 449 & 2.76 & 0.8882 & $\mathrm{H} \rightarrow \mathrm{L}(97)$ & 433 \\
\hline 348 & 3.57 & 0.1219 & $\mathrm{H}-1 \rightarrow \mathrm{L}(75) ; \mathrm{H}-3 \rightarrow \mathrm{L}(20)$ & \\
\hline 296 & 4.20 & 0.0873 & $\mathrm{H}-3 \rightarrow \mathrm{L}(68) ; \mathrm{H}-1 \rightarrow \mathrm{L}(16)$ & - \\
\hline \multicolumn{5}{|l|}{$\mathrm{CHCl}_{3}$} \\
\hline 445 & 2.79 & 0.8686 & $\mathrm{H} \rightarrow \mathrm{L}(100)$ & 431 \\
\hline 346 & 3.58 & 0.1224 & $\mathrm{H}-1 \rightarrow \mathrm{L}(74) ; \mathrm{H}-3 \rightarrow \mathrm{L}(22)$ & \\
\hline 295 & 4.20 & 0.0900 & $\mathrm{H}-3 \rightarrow \mathrm{L}(67) ; \mathrm{H}-1 \rightarrow \mathrm{L}(17)$ & 270 \\
\hline \multicolumn{5}{|l|}{ 1,4-Dioxane } \\
\hline 439 & 2.83 & 0.8574 & $\mathrm{H} \rightarrow \mathrm{L}(96)$ & 424 \\
\hline 339 & 3.66 & 0.1169 & $\mathrm{H}-1 \rightarrow \mathrm{L}(63) ; \mathrm{H}-3 \rightarrow \mathrm{L}(27)$ & \\
\hline 294 & 4.22 & 0.0928 & $\mathrm{H}-3 \rightarrow \mathrm{L}(62) ; \mathrm{H}-1 \rightarrow \mathrm{L}(21)$ & 271 \\
\hline \multicolumn{5}{|l|}{ Toluene } \\
\hline 442 & 2.81 & 0.8769 & $\mathrm{H} \rightarrow \mathrm{L}(97)$ & 427 \\
\hline 340 & 3.64 & 0.1168 & $\mathrm{H}-1 \rightarrow \mathrm{L}(70) ; \mathrm{H}-3 \rightarrow \mathrm{L}(26)$ & \\
\hline 294 & 4.22 & 0.0911 & $\mathrm{H}-3 \rightarrow \mathrm{L}(63) ; \mathrm{H}-1 \rightarrow \mathrm{L}(20)$ & - \\
\hline
\end{tabular}




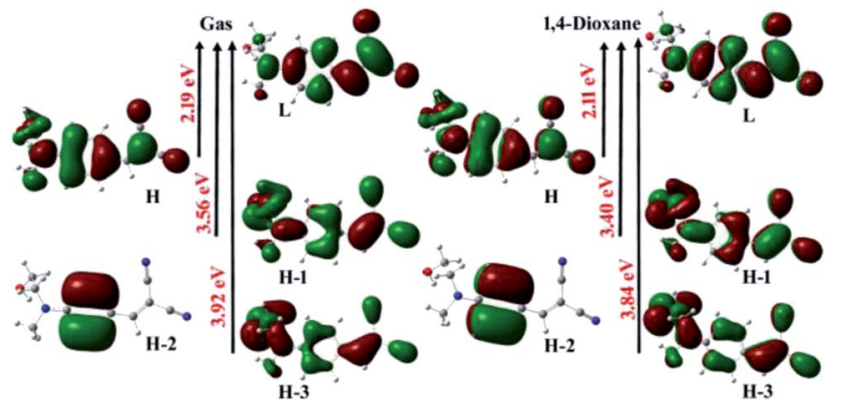

Fig. 4 The important frontier molecular orbitals of HEMABM calculated by using PBEPBE/6-311++G $(d, p)$ level of theory in gas phase and in 1,4-dioxane. The orbitals plotted with isovalue of $0.02 \AA^{-3}$.

The computed solvation energy for HEMABM in different solvents are listed in Table 3 and we found that the solvation energy is increased with increasing the solvent polarity. The very low solvation energy is observed in 1,4-dioxane with $6.64 \mathrm{kcal} \mathrm{mol}^{-1}$ and this may be a reason for the formation of excellent morphology in the 1,4-dioxane mixture.

\subsection{Preparation and characterization of the HEMABM films}

To study the film morphology and optical properties, we prepared solutions with $4.5 \mathrm{mg}$ of the HEMABM in $0.3 \mathrm{ml}$ of different solvents shown in Table 4 . The appropriate solvents were selected based on the solubility test and based on the boiling point of respective solvent. The HEMABM was partially soluble in chlorobenzene, toluene and IPA at room temperature, but the homogeneous solution was obtained at $80^{\circ} \mathrm{C}$. With slow cooling of this mixture into room temperature crystals were appeared in toluene mixture and other solvent mixtures (in $\mathrm{Ph}-\mathrm{Cl}$ and IPA) retained as such.

To investigate the distinctive nature of small molecule HEMABM films from solution-processed, solutions were prepared in $\mathrm{MeOH}$, IPA, EtOAc, THF, $\mathrm{Ph}-\mathrm{Cl}, \mathrm{CHCl}_{3}, 1,4$-dioxane and toluene to analyze its quality and morphology by AFM, Fig. 5. The HEMABM solution preheated at $85{ }^{\circ} \mathrm{C}$ for $20 \mathrm{~min}$ (exception in case of the $\mathrm{MeOH}, \mathrm{CHCl}_{3}$ and THF) was deposited

Table 3 The computed HOMO, LUMO, $\Delta E_{(\mathrm{L}-\mathrm{H})}$ energy (in eV) and solvation energy (in kcal mol ${ }^{-1}$ ) for HEMABM with PBEPBE/6-311++G $(d, p)$ level of theory

\begin{tabular}{lllll}
\hline Solvents & HOMO & LUMO & $\Delta E_{(\mathrm{L}-\mathrm{H})}$ & Solvation energy $^{a}$ \\
\hline Gas & -5.53 & -3.34 & 2.19 & - \\
MeOH & -5.29 & -3.27 & 2.02 & 13.24 \\
IPA & -5.30 & -3.27 & 2.03 & 12.86 \\
$\mathrm{CHCl}_{3}$ & -5.35 & -3.28 & 2.07 & 10.19 \\
EtOAc & -5.33 & -3.28 & 2.05 & 10.91 \\
THF & -5.33 & -3.28 & 2.05 & 11.45 \\
Ph-Cl & -5.33 & -3.28 & 2.05 & 10.77 \\
1,4-Dioxane & -5.41 & -3.30 & 2.11 & 6.64 \\
Toluene & -5.40 & -3.29 & 2.11 & 7.07
\end{tabular}

${ }^{a}$ Energy difference between the optimized structure of the gas phase and in respective solvents.
Table 4 HEMABM solubility properties used in the film's preparations ${ }^{a}$

\begin{tabular}{lll}
\hline Solvent & $\mathrm{rt}$ & $85{ }^{\circ} \mathrm{C}$ \\
\hline $\mathrm{MeOH}$ & $\mathrm{S}$ & $\mathrm{S}$ \\
$\mathrm{IPA}$ & $\delta \mathrm{s}$ & $\mathrm{S}$ \\
$\mathrm{EtOAc}$ & $\mathrm{S}$ & $\mathrm{S}$ \\
$\mathrm{THF}$ & $\mathrm{S}$ & $\mathrm{S}$ \\
$\mathrm{Ph}-\mathrm{Cl}$ & $\delta \mathrm{s}$ & $\mathrm{S}$ \\
$\mathrm{CHCl}_{3}$ & $\mathrm{~s}$ & $\mathrm{~S}$ \\
$1,4-$ Dioxane & $\mathrm{S}$ & $\mathrm{S}$ \\
Toluene & $\delta \mathrm{s}$ & $\mathrm{S}$
\end{tabular}

${ }^{a} \mathrm{rt}=$ room temperature; $\delta \mathrm{s}=$ partially soluble; $\mathrm{s}=$ completely soluble.

on glass substrate, Fig. 6(a). The glass substrate was previously coated with PEDOT:PSS polymer layer with around $40 \mathrm{~nm}$ and dried at $120{ }^{\circ} \mathrm{C}$ for $20 \mathrm{~min}$ to better HEMABM adhesion. The HEMABM films were analyzed by AFM in order to know the quality and morphology. The AFM results suggested that the good homogeneity surface with all the solvents and total coverage area of HEMABM films excepted to the toluene solution (Fig. 6(b)).

In the case of toluene mixture, a star shaped HEMABM crystals were grown in the glass substrate after the drying a couple of hours. The film is not homogeneous, it has gaps, agglomerates and crystals. Only some portion of the film was regular and its morphology has an average roughness of $1.0 \mathrm{~nm}$. The film images at $100 \mu \mathrm{m}$ showed some homogeneous area with small holes and its corresponding image on the left side of the Fig. 7 which showed the needle-shaped crystals formed on the film (Fig. 7). The morphology and roughness of each film with all solvents Table 5 and Fig. 8 are compared at 10-20 $\mu \mathrm{m}$ scale. We can see from the whole films the formation of agglomerates with a length of 10-20 $\mu \mathrm{m}$. However, the most homogeneous films were obtained using $\mathrm{MeOH}$, 1,4-dioxane and $\mathrm{Ph}-\mathrm{Cl}$, but on a smaller scale in homogeneous areas the morphology is comparable.

The Fig. 9 shows the absorption and photoluminescence of the films for each solvent used. The $\lambda_{\max }$ absorption maximum

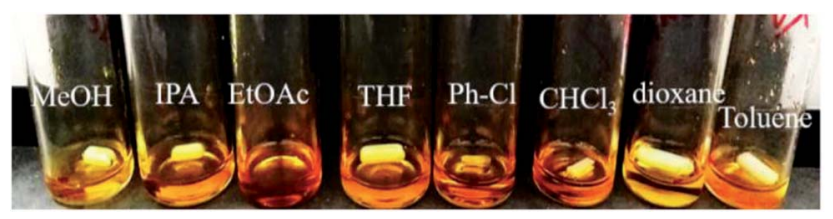

Fig. 5 The HEMABM in different solvents.

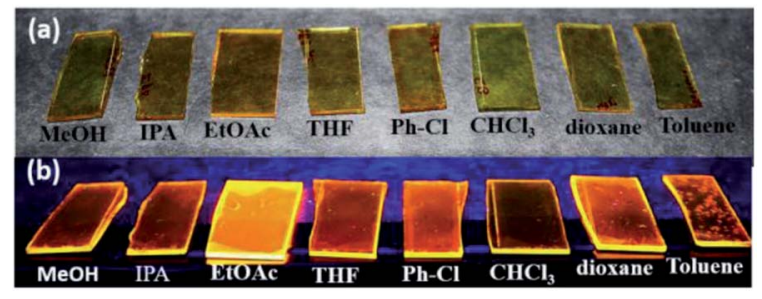

Fig. 6 HEMABM film under (a) normal light and (b) UV-vis lamp. 


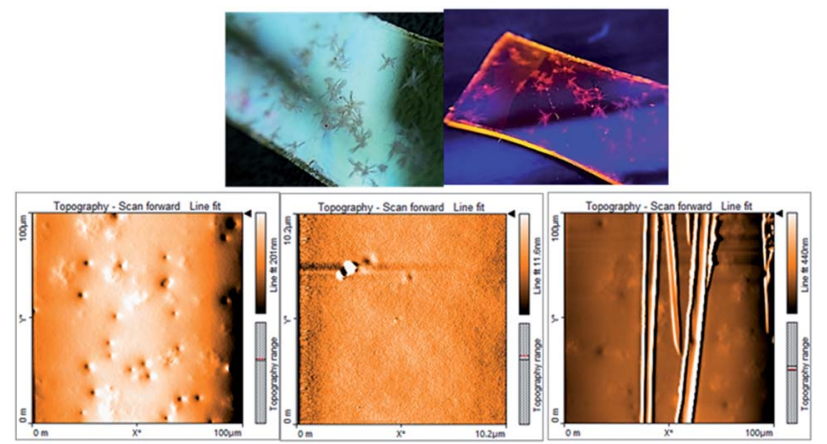

Fig. 7 Representative AFM of the morphology for HEMABM solution deposited and HEMABM crystals.

Table 5 Average roughness of HEMABM film by solution with different solvents

\begin{tabular}{lcl}
\hline & \multicolumn{2}{c}{ Roughness $(\mathrm{nm})$} \\
\cline { 2 - 3 } Solvents & Scan area $^{a}$ & Scan area $^{b}$ \\
\hline $\mathrm{MeOH}$ & 8.11 & 1.302 \\
$\mathrm{IPA}$ & 16.04 & 1.464 \\
EtOAc & 9.40 & 1.200 \\
THF & 10.16 & 1.202 \\
Ph-Cl & 9.12 & 0.556 \\
CHCl $_{3}$ & 9.99 & 0.905 \\
1,4-Dioxane & 11.47 & 0.651 \\
Toluene & 33.05 & 0.933
\end{tabular}

${ }^{a} 10 \times 10 \mu \mathrm{m} .{ }^{b} 20 \times 20 \mu \mathrm{m}$.

(a)
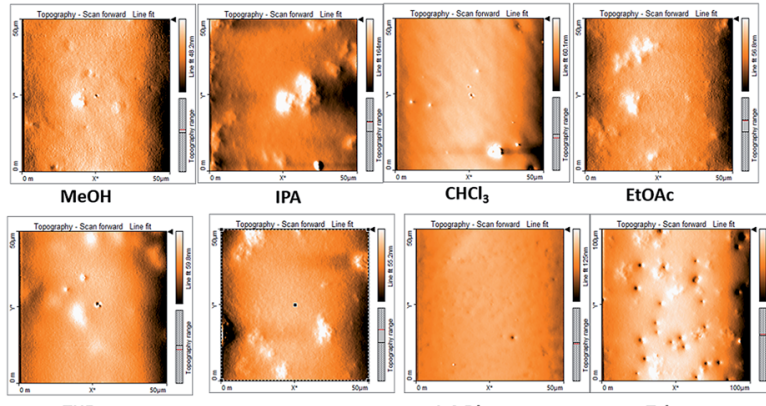

Ph-Cl

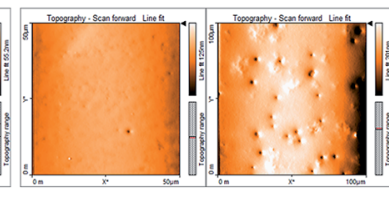

(b)
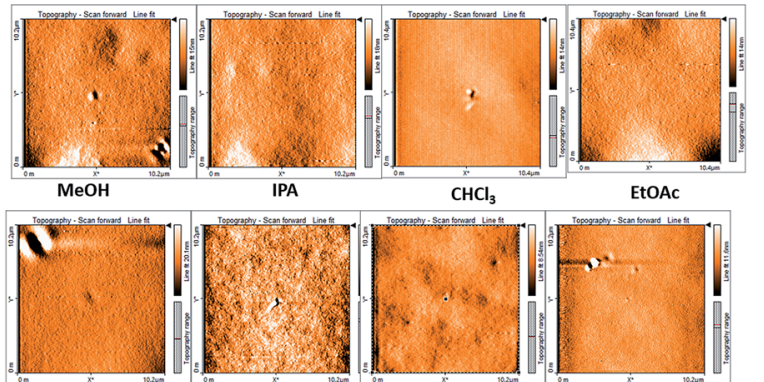

THF
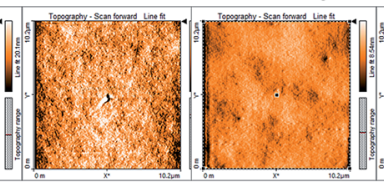

1,4-Dioxane

$\mathrm{Ph}-\mathrm{Cl}$

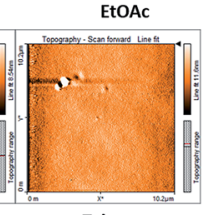

Toluene

Fig. 8 Representative AFM image of the morphology for films of compound HEMABM at (a) $10 \mu \mathrm{m}$ scale and (b) $20 \mu \mathrm{m}$ scale.
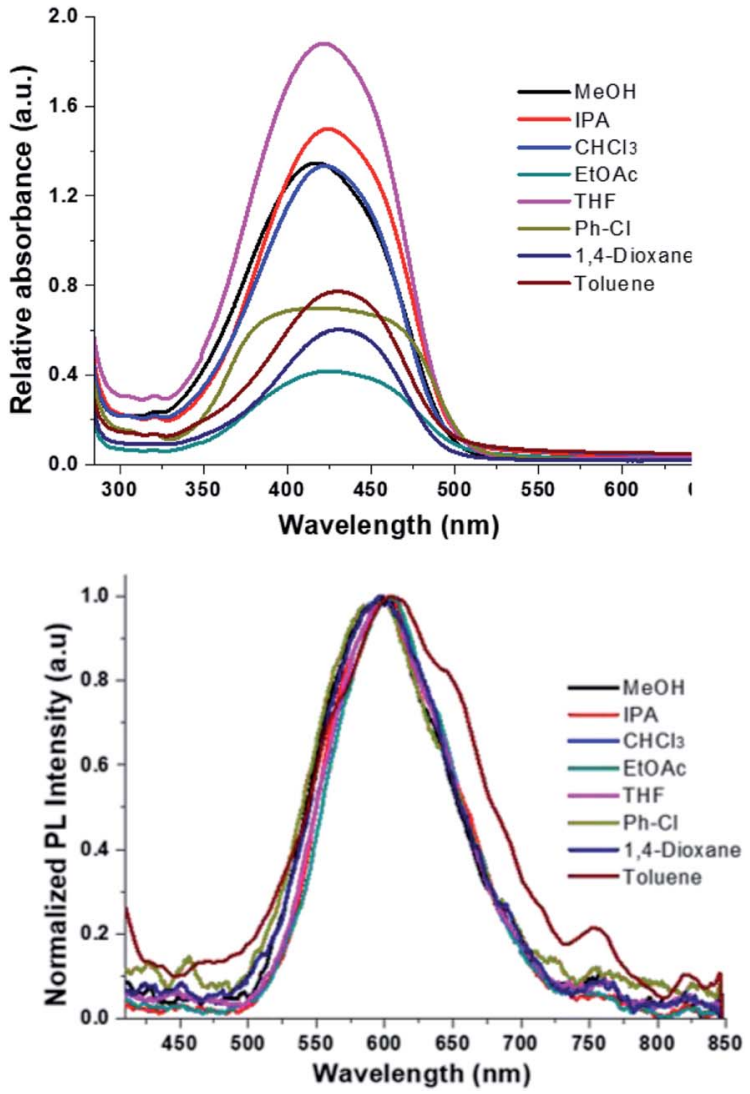

Fig. 9 HEMABM absorption and PL emissions spectra of the films (glass substrate) prepared with all solvents.

is between $420 \mathrm{~nm}$ and $434 \mathrm{~nm}$ for $\mathrm{MeOH} \rightarrow \mathrm{Ph}-\mathrm{Cl}$, it was not observed a solvent effect on absorption wavelength at $421 \mathrm{~nm}$, which corresponding to the transition observed for HEMABM in solution, only the band shape is broad, as it was expected for solid state..$^{30,42}$

From film thickness the HEMABM concentration was calculated for best comparison of the absorption and photoluminescence, Table 6. However, the spectra did not show the absorption below $300 \mathrm{~nm}$ as observed in the solution spectra (see Fig. 9), so the solution were deposited on quartz substrate.

Table 6 HEMABM films with different thickness, absorbance and concentration

\begin{tabular}{llllll}
\hline Solvent & $\begin{array}{l}\text { Thickness } \\
(\mathrm{nm})\end{array}$ & $\begin{array}{l}{[\text { HEMABM }]} \\
\times 10^{-5} \mathrm{M}\end{array}$ & $I_{\max }$ & $\begin{array}{l}\text { Abs. } 155 \\
\mathrm{~nm}\end{array}$ & Abs. $^{a}$ \\
\hline $\mathrm{MeOH}$ & 155 & 4.37 & 1.33 & 1.330 & 1 \\
$\mathrm{IPA}$ & 232 & 3.08 & 1.48 & 0.989 & 0.743 \\
$\mathrm{CHCl}_{3}$ & 250 & 2.05 & 1.32 & 0.818 & 0.615 \\
EtOAc & 242 & 6.48 & 1.88 & 1.204 & 0.905 \\
THF & 235 & 3.18 & 0.69 & 0.455 & 0.342 \\
Ph-Cl & 187 & 1.11 & 0.6 & 0.497 & 0.374 \\
1,4-Dioxane & 165 & 1.15 & 0.77 & 0.723 & 0.544 \\
Toluene & 200 & 0.897 & 0.4 & 0.310 & 0.233
\end{tabular}

${ }^{a}$ Normalized values [intensity absorbance/thickness]; $I=$ intensity (Abs. at $\lambda=421 \mathrm{~nm}$ ). 


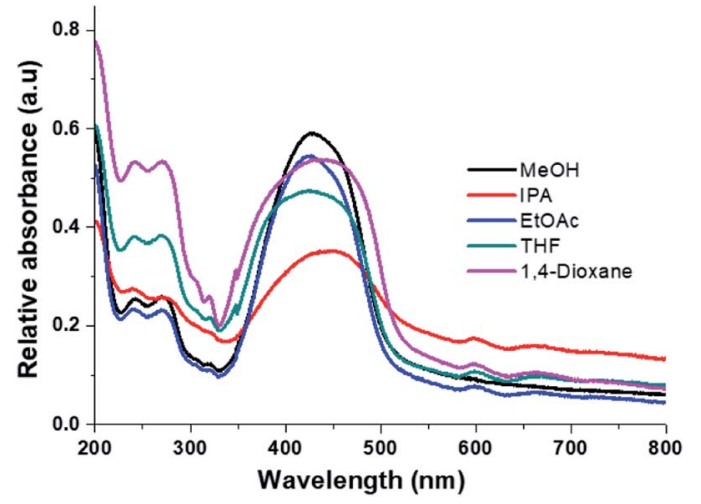

Fig. 10 HEMABM absorption spectra of the films (quartz substrate) prepared with different solvents.

The spectra are shown in Fig. 10, and it shows that the absorption in the range $215-300 \mathrm{~nm}$ appeared as the transitions described earlier in solution. Also, it is interesting note that with the solvent 1,4-dioxane the band intensity is higher than with $\mathrm{MeOH}$, which is an indication to the molecules interaction.

\subsection{OLED preparation and characterization}

To prepare the OLED and to compare to the MEH-PPV, the deposition was performed at the same conditions. The Fig. 11(a) showed the emission under the UV-vis lamp of the films of

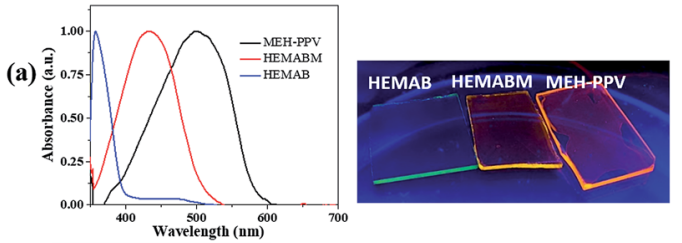

(b)
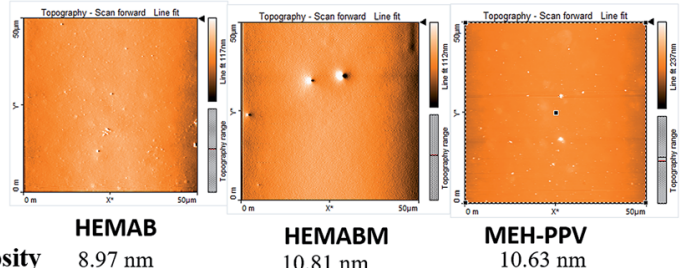

Rugosity $\quad 8.97 \mathrm{~nm}$
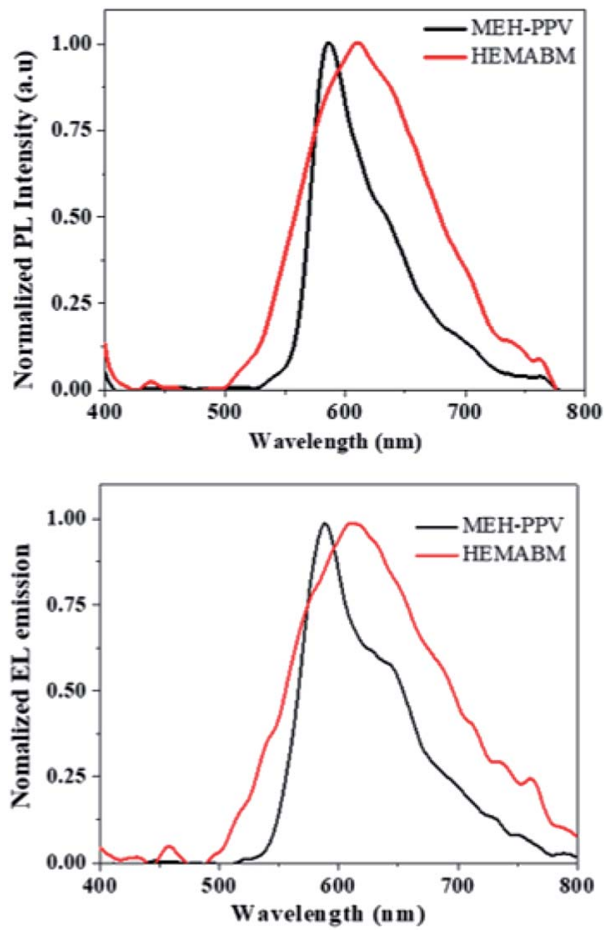

Fig. 13 Photoluminescence and electroluminescence emission of the film and OLED based on MEH-PPV and HEMABM.

Fig. 11 (a) Film under the UV-vis lamp and absorption spectra of the films with $M E H-P P V, H E M A B M$ and $H M A B$ reagent respectively. (b) AFM image of the morphology for films of compound $H E M A B$, HEMABM compound and MEH-PPV respectively.
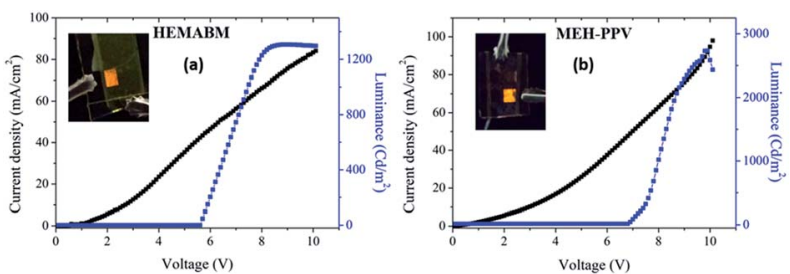

Fig. 12 Luminance and J-V curves for OLED based on (a) compound HEMABM and (b) compound MEH-PPV.

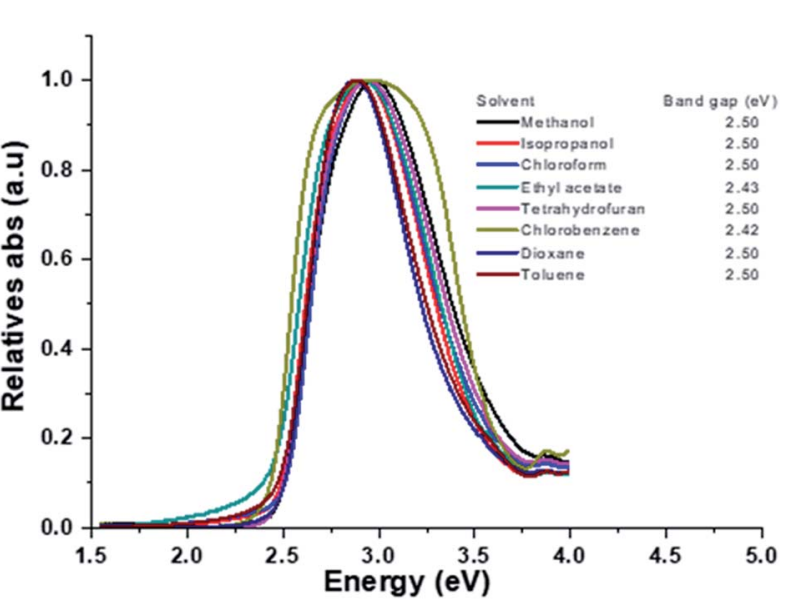

Fig. 14 Spectra of HEMABM on film and the values of the band gap.

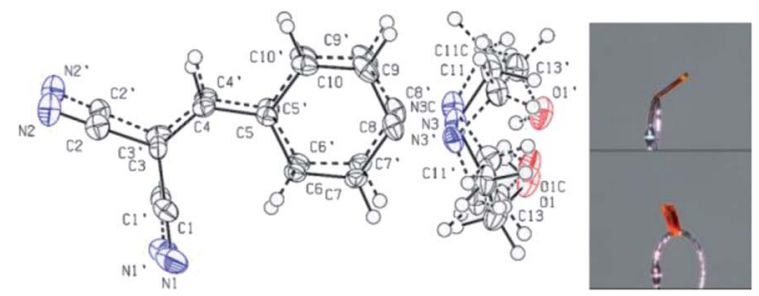

Fig. 15 The ORTEP molecular structure of HEMABM, with displacement ellipsoids drawn at the $50 \%$ probability level. The photo shows the orange color of the crystal. 


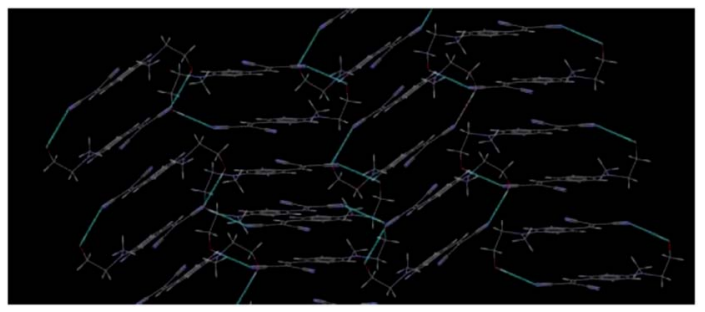

Fig. 16 Crystal packing diagram of HEMABM showing the intermolecular interaction between $-\mathrm{CN}$ and $\mathrm{O}-\mathrm{H}$ groups. ${ }^{51}$

reagent 4-((2-hydroxyethyl)(methyl)amino)benzaldehyde [HEMAB] and Fig. 11(b) showed the best morphology obtained. We can see the differences of the absorption maxima wavelength for HEMAB reagent, HEMABM and MEH-PPV. However, it was unexpected the emission wavelength of the title small molecular weight HEMABM compared to commercial MEH-PPV are closer and the difference about $67 \mathrm{~nm}$. But the quantum yield measured gave a value of $7.99 \%$ for HEMABM and $15.25 \%$ for MEH-PPV.

Fig. 12 shows representative electrical parameters for devices with HEMABM compounds as well as MEH-PPV. The threshold voltage for devices based on MEH-PPV was slightly lower. These low threshold voltages can be compared with those reported by $\mathrm{Ha}^{\mathbf{4 3}}$ and Hewidy ${ }^{\mathbf{4 4}}$ for OLEDs with MEH-PPV as emitting layer. The luminance for devices based on HEMABM was of about $1300 \mathrm{~cd} \mathrm{~m}^{-2}$ meanwhile for MEH-PPV was about $2600 \mathrm{~cd} \mathrm{~m}^{-2}$. Also, it is observed that the electroluminescence wavelength (EL) of OLEDs corresponded to the PL wavelength $\left(\lambda_{\mathrm{em}} 611\right)$ and $586 \mathrm{~nm}$ for HEMABM and MEH-PPV respectively, Fig. 13.

Fig. 14 shows the graphics with the measurement of the optical band gap for the compound HEMABM. The band gap of

Table 7 Hydrogen-bonds $D \cdots H \cdots A(\AA)$ and $D-H \cdots A$ angles $\left({ }^{\circ}\right)$ of compound HEMABM ${ }^{47,48}$

\begin{tabular}{lllll}
\hline $\mathrm{D}-\mathrm{H} \cdots \mathrm{A}$ & $d(\mathrm{D}-\mathrm{H})$ & $d(\mathrm{D} \cdots \mathrm{A})$ & $<\mathrm{DHA}$ & Symm. op. 2 \\
\hline $\mathrm{O}(1) \cdots \mathrm{N}(2)$ & $\mathrm{O}(1)-\mathrm{H}(1)$ & $\mathrm{N} 2 \cdots \mathrm{H} 1$ & $\mathrm{O}(1)-\mathrm{H}(1) \cdots \mathrm{N} 2$ & $-x,-y, 1-z$ \\
3.022 & 0.8400 & 2.182 & 173.94 & \\
$2.5-3.2$ & & $1.5-2.2$ & $170-180$ &
\end{tabular}

Table 8 Selected bond lengths of the HEMABM

\begin{tabular}{lc}
\hline Bond & Length $(\AA)$ \\
\hline $\mathrm{C}(3)-\mathrm{C}(4)$ & $1.373(6)$ \\
$\mathrm{C}(4)-\mathrm{C}(5)$ & $1.430(7)$ \\
$\mathrm{C}(5)-\mathrm{C}(6)$ & $1.414(7)$ \\
$\mathrm{C}(5)-\mathrm{C}(10)$ & $1.418(7)$ \\
$\mathrm{C}(6)-\mathrm{C}(7)$ & $1.371(7)$ \\
$\mathrm{C}(7)-\mathrm{C}(8)$ & $1.415(4)$ \\
$\mathrm{C}(8)-\mathrm{N}(3)$ & $1.402(6)$ \\
$\mathrm{C}(8)-\mathrm{C}(9)$ & $1.423(6)$ \\
$\mathrm{C}(9)-\mathrm{C}(10)$ & $1.372(7)$
\end{tabular}

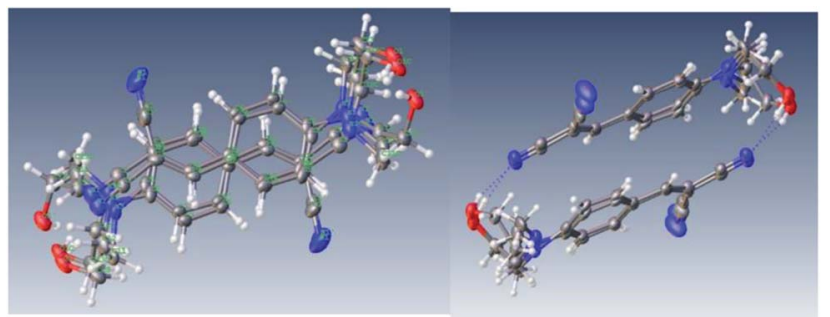

Fig. 17 Perspective view of the molecular structures showing weak $\pi \cdots \pi$ interactions and $\mathrm{O}-\mathrm{H} \cdots \mathrm{N}$ interactions. ${ }^{49}$

the MEH-PPV from different reports, ${ }^{\mathbf{4 4 , 4 5}}$ is in the ranges between 2.00 and $2.10 \mathrm{eV}$. The values were estimated using onset wavelength. The HEMABM absorption value of $\lambda_{\max }$ and $\lambda_{\text {em }}$ calculated using optoelectronic module of Schrödinger Material Suite. ${ }^{46}$ gave the values at $390 \mathrm{~nm}$ and $735 \mathrm{~nm}$ respectively (Table $\mathrm{S} 4 \dagger)$. The band gap is $2.92 \mathrm{eV}(\mathrm{HOMO}(\mathrm{eV})=$ -6.1399 and LUMO $(\mathrm{eV})=-3.2087)$.

\subsection{Single crystal X-ray crystallography}

The compound HEMABM crystallizes in the monoclinic system with the space group $P 2_{1} / n$ with $Z=4$. The ORTEP representation of this compound is shown in Fig. 15. The crystal data and structure refinement parameters are presented in Table S1, $\dagger$ and the geometrical parameters for this compound are summarized in Tables S2 and S3. $\dagger$

Single crystal X-ray diffraction analysis revealed that HEMABM crystals exhibited a structure with disordered over either two or three orientations. The fragment $\mathrm{C} 1>\mathrm{C} 10$ (including N1 and N2) is disordered over two orientations, and the occupancy factor of the major component of the disorder refines to $0.598(13)$. The fragment N3 > O1 (including C11, C12 and $\mathrm{C13}$ ) is disordered over three orientations, and the occupancy factors of the three components refine to 0.531(3), $0.2429(19)$ and $0.227(3)$ (Fig. 15).

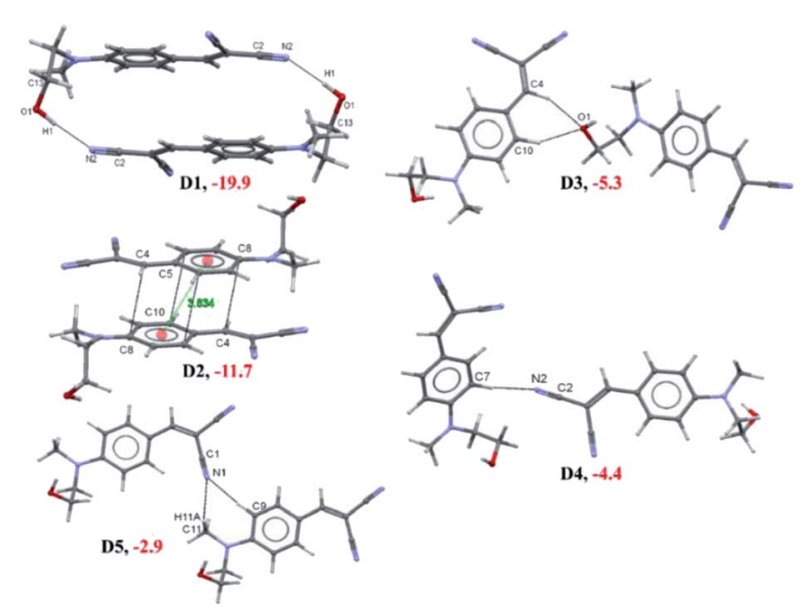

Fig. 18 Different interacting dimers (D1-D5) in the crystal structure of HEMABM along with the interaction energies. 


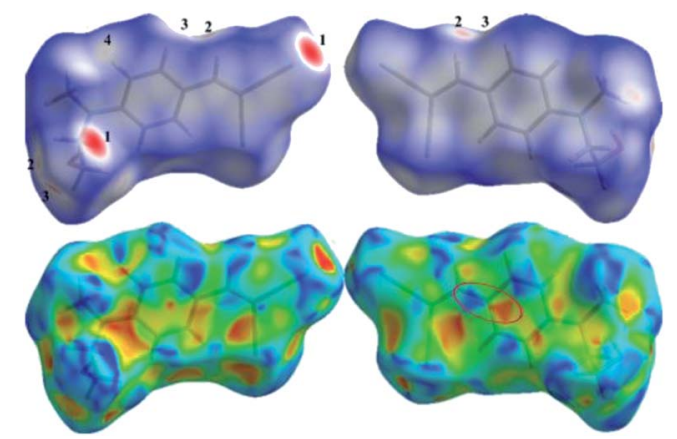

Fig. 19 Views of the Hirshfeld surfaces mapped with $d_{\text {norm }}$ in two different orientations for HEMABM in top side of the figure. The significant contacts are labelled closer to corresponding atoms. The shape index diagrams for HEMABM in two different orientations are shown in the bottom side of the figure.

The disorder may be due to intermolecular interaction between the -OH group of $\mathrm{N}$-methylethanol moiety's and one of the $-\mathrm{CN}$ group of malononitrile moiety in the other molecule. This interaction is a key interaction for the formation of molecular packing which forming a macrocyclic ring with $R_{2}^{2}(22)$ motif (Fig. 16) and the intermolecular interaction $\mathrm{O}-\mathrm{H} \cdots \mathrm{N}$ could be mainly was observed in the crystal packing of HEMABM, Table 7. These interactions affect the bond length corresponding to $\mathrm{C} \equiv \mathrm{N}$ group. $\mathrm{N}(1)$ $\equiv \mathrm{C}(1)$ and $-\mathrm{C}(2) \equiv \mathrm{N}(2)$ bond are of 1.138(7) $\AA$ and 1.156(7) $\AA$ respectively. (For $\mathrm{N}\left(1^{\prime}\right) \equiv \mathrm{C}\left(1^{\prime}\right)$ and $\mathrm{N}\left(2^{\prime}\right) \equiv \mathrm{C}\left(2^{\prime}\right)$ bonds of 1.161(11) $\AA$ and 1.136(10) A respectively) Table 8. The values for $\mathrm{N}(1) \equiv \mathrm{C}(1)$ and $\mathrm{N}\left(2^{\prime}\right) \equiv \mathrm{C}\left(2^{\prime}\right)$ are within the reported values for $\mathrm{C}_{\mathrm{ar}}-\mathrm{C} \equiv \mathrm{N},{ }^{47}$ but for the $\mathrm{N}(2) \equiv \mathrm{C}(2)$ and $\mathrm{N}\left(1^{\prime}\right) \equiv \mathrm{C}\left(1^{\prime}\right)$ distances are larger due to hydrogen bonds distances, $a$, due to the atoms involved in chain motif formation..$^{47}$ This bond length variation is might be due to the charger transfer between the interacting functional groups and similar bond length variation is also observed in the phenyl ring affected by the donor group methylaminoethanol and the acceptor group malononitrile (Table 8), contributing to the disorder that exhibit the molecular structure and the dimers observed in the package, ${ }^{48}$ Fig. 15.

The arrangement of the molecules in the crystal is not completely face-to-face manner, Fig. 16 . The dimer showed a weak interaction between aromatic rings; with two centroid-centroid distances: one of $3.834 \AA$ (shift distance of $1.872 \AA$ ) and $3.917 \AA$ (shift distance of $1.905 \AA$ ), which were calculated using OLEX $2 .^{49}$ This $\pi$ stacked dimer is shown in Fig. 17, and these parameters for the $\pi \cdots \pi$ interaction is found in the range of typical stacking interaction $(<4.00 \AA$ and offsets of 1.6-1.8 ̊̊). ${ }^{50}$

\subsection{Characterization of intermolecular interaction}

To find out the charge transfer between the $-\mathrm{C} \equiv \mathrm{N}$ and $-\mathrm{OH}$ group, we carried out the NBO analysis for most stabilized dimer (D1) which formed by the strong $\mathrm{O}-\mathrm{H} \cdots \mathrm{N}$ intermolecular interaction. The NBO analysis suggested that the charge transfer between the lone pair electron of $\mathrm{N}(2)$ atom 


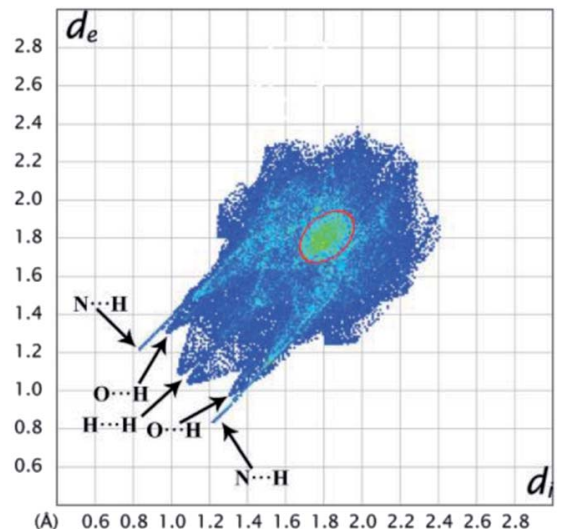

Fig. 20 The $2 \mathrm{D}$ finger print for HEMABM and the significant contacts is labelled.

into the antibonding orbital of $\mathrm{O} 1-\mathrm{H} 1(\mathrm{O})$ bond which is stabilized with $6.00 \mathrm{kcal} \mathrm{mol}^{-1}$. The energetically significant dimers (D1-D5) are extracted from the crystal packing of HEMABM using PIXEL method and these dimers are shown in Fig. 18 along with their intermolecular interaction energy $\left(E_{\text {tot }}\right)$. The $E_{\text {tot }}$ for D1-D5 is in the range of -19.9 to $-2.9 \mathrm{kcal} \mathrm{mol}^{-1}$ (Table 9). The strongest stabilizing dimer D1 in HEMABM is formed by the symmetrical $\mathrm{O} 1-\mathrm{H} 1 \cdots \mathrm{N} 2$ interactions between the $-\mathrm{OH}$ and $-\mathrm{CN}$ group $\left(E_{\mathrm{tot}}:-19.9 \mathrm{kcal} \mathrm{mol}^{-1}\right)$. Fig. 18 and Table 9. Based on the NBO analysis, we conclude that this (O1-H1 $\cdots \mathrm{N} 2)$ interaction is a key contact for intermolecular charge transfer as mentioned earlier. The two neighbouring D1 dimers are sidewise interconnected by the $\pi$ stacking dimer $(\pi \cdots \pi$ interaction, $\mathrm{D} 2, E_{\text {tot }}:-11.7 \mathrm{kcal} \mathrm{mol}^{-1}$ ) between the two-phenyl ring with the centroid to centroid distance is 3.834 A. Also, two adjacent D1 dimers in the up and down manner are interconnected by the $\mathrm{C} 4-\mathrm{H} 4 \cdots \mathrm{O} 1$ and $\mathrm{C} 10-\mathrm{H} 10 \cdots \mathrm{O} 1$ interactions in D3 ( $E_{\text {tot }}$ : $\left.-5.3 \mathrm{kcal} \mathrm{mol}^{-1}\right)$ and the $\mathrm{C} 7-\mathrm{H} 7 \cdots \mathrm{N} 2$ interaction in $\mathrm{D} 4\left(E_{\mathrm{tot}}\right.$ : $-4.4 \mathrm{kcal} \mathrm{mol}^{-1}$ ). In the former interactions, $\mathrm{C} 4-\mathrm{H} 4 \cdots \mathrm{O} 1$ and C10-H10 $\cdots \mathrm{O} 1$, forming a $R_{1}{ }^{2}(6)$ motif, while a latter interaction, $\mathrm{C} 7-\mathrm{H} 7 \cdots \mathrm{N} 2$, form a $\mathrm{C}(8)$ chain. Both dimers, D3 and D4, link the neighbouring molecules into chain which propagate parallel to the $b$ axis. Another two weak C11-H11A $\cdots \mathrm{N} 1$; C9H9 $\cdots \mathrm{N} 1$ (D5, $E_{\text {tot }}:-2.9 \mathrm{kcal}$ mol-1) interactions links the neighbouring molecules with $R_{1}^{2}(7)$ motif into form a chain which runs parallel to $c$ axis. The combinations of interactions in dimers D1-D3 are key contacts to form a sandwich herringbone architecture in overall packing (Fig. 21(a)).

Another 2D molecular layers are formed by the combinations of interaction in dimers D3-D5 which propagates along the $b c$ plane (Fig. 21(b)). It is worthy noted that all the dimers (D1-D5) are predominately stabilized with electrostatic contribution in the range of $60-65 \%$ except in D2. The dimer D2, mainly stabilized with dispersion contribution (67\%) because it is a $\pi$ stacking dimer. The total lattice energy for HEMABM is $-32.2 \mathrm{kcal} \mathrm{mol}^{-1}$, and the dispersion (52\%) and electrostatic $(48 \%)$ is contributions are approximately equal in stabilizing the crystal structure.

Further, to qualitatively analyse the intermolecular interactions present in the title molecule, we performed HS analysis and 2D fingerprint plots. The HS diagram and shape index (SI) of HEMABM is shown in Fig. 19. In HS diagram shown bright red color spot for $\mathrm{O} 1-\mathrm{H} 1 \cdots \mathrm{N} 2(\mathrm{D} 1)$; C4-H4 $\cdots \mathrm{O} 1$; C10-H10 $\cdots$ O1(D3) and C9-H9 $\cdots \mathrm{N} 1$ (D5) interactions which are labelled in Table 9. The SI diagram shows that the red and blue color triangles on the surface of phenyl ring is due to the $\pi$ stacking

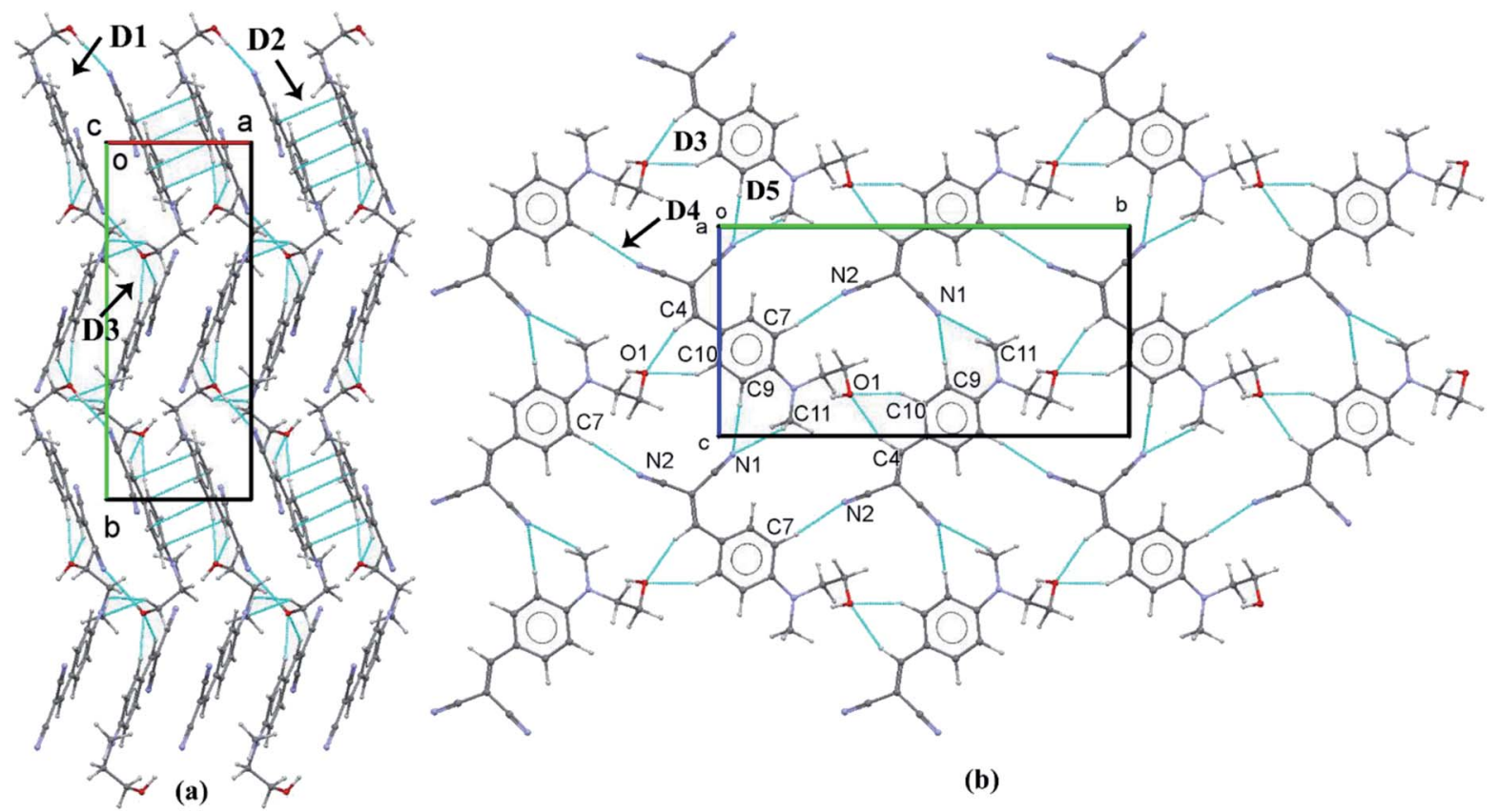

Fig. 21 (a) The crystal packing diagram of HEMABM; (b) part of crystal packing of HEMABM showing the molecular layered structure formed by the combinations of interactions in D3-D5. 
interactions (D2) in HEMABM structure. The 2D decomposed FP plot show the relative contribution of various intermolecular contacts in HEMABM is shown in Fig. 20. The $\mathrm{H} \cdots \mathrm{H}$ contacts are predominated in the crystal $(35.8 \%)$ and it was shown as a double spike in $d_{\mathrm{e}}=d_{\mathrm{i}} \cong 1.1 \AA$. The second significant intermolecular contacts are $\mathrm{N} \cdots \mathrm{H}$ with a contribution of $29.9 \%$ and it shown as a sharp spike at $d_{\mathrm{e}}=d_{\mathrm{i}} \cong 1.2 \AA$. The $\mathrm{C} \cdots \mathrm{H}$ and $\mathrm{O} \cdots \mathrm{H}$ contacts are contributing $14.3 \%$ and $6.9 \%$ of total surface. It noted that the contribution of $\mathrm{C} \cdots \mathrm{C}$ contacts is comparably higher $(10.1 \%)$ than the $\mathrm{O} \cdots \mathrm{H}$ contacts $(6.9 \%)$ in the crystal structure and these $\mathrm{C} \cdots \mathrm{C}$ contacts are concentrated around $d_{\mathrm{e}}=d_{\mathrm{i}} \cong 1.8 \AA$ as a green $\operatorname{dot}$ (it highlighted in red color circle) which indicate the existence of $\pi$ stacking interaction in HEMABM.

\section{Conclusion}

The low molecular weight malononitrile derivative synthesized and comprehensively characterized. Despite being a very small molecule its optoelectronic properties are very similar to the commercial MEH-PPV. The importance of the intramolecular interactions in the structure and intermolecular interactions with the solvent affecting the optical properties of the reported compound but it helps to find that best conditions to obtain a film with this low molecular weight compound and suitable morphology to optoelectronic devices. The results show that although the absorptions are different between HEMABM and MEH-PPV, the emission is approximately at the same wavelength, which could be due to the intermolecular interaction of HEMABM, and therefore a good candidate with potential for applications in compare to the commercial MEH-PPV. From the structure of compound, the phenyl ring linked to dicyanovinylene group significantly raise the photoluminescence quantum yields in film. In summary, malononitrile derivatives considering their EL spectra, seem to be the most promising for further investigations aiming at both device and molecule structure modifications and registration of OLED parameters.

\section{Experimental section}

\subsection{Chemicals and instruments}

4-Fluorophenylacetonitrile (analytical grade, 99\%), malononitrile (analytical grade, 99\%) were purchased from Aldrich Chemical Co. (Mexico) and $\mathrm{K}_{2} \mathrm{CO}_{3}$ from J.T. Baker. The DMSO, EtOH were acquired from Fermont. The reagents and solvents were used as received without any additional purification. Fourier-transform infrared spectrometry (FT-IR). The IR spectra of the compounds were recorded from neat solids on a Vertex model 70 Bruker 750 FT-IR spectrophotometer with ATR (Attenuated Total Reflection). The spectra were collected from 4000 to $400 \mathrm{~cm}^{-1}$ with a $4 \mathrm{~cm}^{-1}$ spectral resolution. Proton nuclear magnetic resonance $\left({ }^{1} \mathrm{H}-\mathrm{NMR}\right)$. The spectra were recorded using a Bruker $500 \mathrm{MHz}$ NMR spectrometer. Mass spectrometry. The EI spectra were obtained using a Mass Spectrometer Jeol MStation 700-D. PEDOT:PSS was acquired from Heraeus Clevios, ITO/glass with resistivity of $10 \mathrm{ohms} \square^{-1}$ was obtained from Delta Technologies.
The current density versus voltage $(J-V)$ and luminous efficiency versus voltage $(L-V)$ curves were measured simultaneously using a power supply (Newark element I4, Keithley 2400) with an in-house-designed and calibrated detection system. The $J-V$ curve is recorded by direct processing of data acquired from the used Keithley 2400 apparatus. Luminous density is estimated through the voltage delivered by a photodiode located at fixed distance from the OLED. Photodiode calibration was performed by using the luminance of commercial LEDs, at different wavelengths and considering all geometrical parameters involved in the detection system.

\subsection{Solution process and device preparation}

The compound was deposited at $2000 \mathrm{rpm}$. For the study, the compounds were prepared solutions with $15 \mathrm{mg} \mathrm{ml}^{-1}$ in $\mathrm{MeOH}$, IPA, EtOAc, 1,4-dioxane, THF, $\mathrm{CHCl}_{3}$, $\mathrm{Ph}-\mathrm{Cl}$ or toluene solvents. At room temperature, the compound HEMABM was in soluble in some solvents, but by heating it was completely soluble. The films were deposited on ITO substrate with a PEDOT:PSS film at $85{ }^{\circ} \mathrm{C}$ and dried for $20 \mathrm{~min}$.

The OLEDs fabrication, it architecture was glass/ITO/ PEDOT:PSS/emissive layer/cathode. The PEDOT:PSS layer (50 $\mathrm{nm}$ ) was deposited by spin coating and dried 10 minutes at $120{ }^{\circ} \mathrm{C}$ and normal atmosphere. The emissive layer (about 80 $\mathrm{nm}$ ) was deposited from a solution with dioxane as solvent for compound HEMABM and chlorobenzene for MEH-PPV; $20 \mathrm{mg}$ $\mathrm{ml}^{-1}$ and $5 \mathrm{mg} \mathrm{ml}^{-1}$ respectively. The solutions and substrates were pre-heated at $85{ }^{\circ} \mathrm{C}$, films were dried also at $85{ }^{\circ} \mathrm{C}$ in normal atmosphere. As cathode $100 \mathrm{~nm}$ of $\mathrm{Al}$ were thermal evaporated also the eutectic alloy of $\mathrm{Bi}:$ In : Sn (melting point $65{ }^{\circ} \mathrm{C}$ ) was deposited at $100{ }^{\circ} \mathrm{C}$ in normal atmosphere by drop casting.

\subsection{Absorbance and emission (UV-vis and PL)}

The absorbance spectra were measured using a spectrometer SD2000 (Ocean Optics, Dunedin, FL) equipped with a pulse xenon light source P-2 (Ocean Optics for the UV region (220-270 $\mathrm{nm})$ ) and a Spectrometer Cary 300 (Agilent) equipped with a deuterium and halogen lamps. For powder samples, the absorption spectra were measured with $\mathrm{KBr}$ pellets using a DT $1000 \mathrm{CE}$ light source (Analytical Instrument Systems, Inc., Flemington, NJ). Emission spectra (PL) were acquired from a QEPro-FL (Ocean Optics, Dunedin, FL) equipped with a laser diode excitation source at a wavelength of $405 \mathrm{~nm}$. The quantum yield $\left(\Phi_{\mathrm{f}}\right)$ for the compounds was determined as described by De Mello ${ }^{52}$ with slight modification. For fluorescence spectra measurements, the powder samples (prepared from crystals) and films. The $J-V$ curves were acquired with a source-meter Keithley 2400 with LabVIEW interface. Electroluminescence spectra were recorded with an Ocean Optics spectrometer. For the photoluminescence spectra a UV-Lamp Mineral Light with emission at $350 \mathrm{~nm}$ was used as excitation source. The morphology and thickness were analyzed using atomic force microscopy (AFM) with the microscope EasyScan 2 from Nanosurf operating in contact mode under ambient 
conditions. This has a maximum square scanning area of 110 $\mu \mathrm{m}$.

\subsection{Single crystal X-ray diffraction (SCXRD)}

All reflection intensities were measured at 110(2) K using a SuperNova diffractometer (equipped with Atlas detector) with CuK $\alpha$ radiation $(\lambda=1.54178 \AA)$ under the program CrysAlisPro. ${ }^{53}$ The same program was used to refine the cell dimensions and for the data reduction. The structure was solved with the program SHELXS-2014/7 (ref. 54) and was refined on $F^{2}$ with SHELXL-2014/7. ${ }^{55}$ Analytical numeric absorption correction using a multifaceted crystal model was applied using CrysAlisPro. The temperature of the data collection was controlled using the system Cryojet (manufactured by Oxford Instruments). The $\mathrm{H}$ atoms were placed at calculated positions using riding model the structure is disordered.

\subsection{Quantum chemical calculations}

All the quantum chemical calculations were performed with the Gaussian 09 program. ${ }^{56}$ The structures were fully optimized with PBEPBE/6-311++G (d, p) level of theory. ${ }^{57-59}$ The vibrational frequency was calculated for the optimized geometry in vacuum and in solvent phases to determine the energy minima on the potential energy surface and no imaginary frequencies were found. All the solution phase calculations were carried out by using the conductor-like polarizable continuum model (CPCM). ${ }^{6,61}$ Time-dependent DFT (TDDFT) ${ }^{62}$ was used to calculate the absorption properties from the optimized geometries with PBEPBE/6-311++G (d, p) level of theory. We performed natural bond orbital (NBO) analysis to characterize the nature of charge transfer between the molecules. Furthermore, the interaction energies $\left(\Delta E_{\mathrm{cp}}\right)$ for the selected molecular dimers at their crystal geometry were calculated at M06-2X ${ }^{63,64}$ cc-PVTZ level of theory with Grimme's D3 dispersion corrections. ${ }^{65}$ The $\Delta E_{\text {cp }}$ was corrected for basis set superposition error (BSSE). ${ }^{66}$

\subsection{Hirshfeld surface analysis and PIXEL energy calculation}

The Hirshfeld surfaces (HS) analysis ${ }^{67-72}$ and the decomposed two-dimensional fingerprint plots $(\mathrm{FP})^{72}$ was used to quantify and to understand the nature of different intermolecular interactions existing in the crystal structure. The HS and FP were generated using the program CrystalExplorer17. ${ }^{73}$ For, PIXEL and Hirshfeld analysis, we used only major disorder fragment. Further, the intermolecular interaction energies $\left(E_{\text {tot }}\right)$ for different molecular pairs of HEMABM were calculated using the PIXEL method (in the CLP computer program package version 12.5.2014). Based on the $E_{\text {tot }}$ values, the selected molecular pairs were considered for further analysis. The total lattice energy of the title compound was also computed using the PIXEL method. The $\mathrm{C}-\mathrm{H}$ bond lengths were adjusted to typical neutron diffraction values $(\mathrm{C}-\mathrm{H}=1.089 \AA)$ before the HS and PIXEL calculations. For PIXEL calculations, the electron density of the molecules was obtained at MP2/6-31G** level of theory using Gaussian09 for all the molecules in the current study.

\section{Conflicts of interest}

There are no conflicts to declare.

\section{Acknowledgements}

The authors wish to express their gratitude to VIEP-BUAP (project PEZM-NAT16-G), to project fellowship-PRODEP-SEP 511-6/17-11066 and 511-6/18-16257, to Maxime Siegler for the X-ray determination, Laboratorio Nacional de Supercómputo del Sureste (LNS-BUAP) to perform the calculations as well as to Vladimir Carranza for technical assistance with mass spectrometry.

\section{Notes and references}

1 P. Stallinga, H. L. Gomes, M. Murgia and K. Müllen, Org. Electron., 2002, 3, 43-51.

2 J. Lei, W. Liang, C. J. Brumlik and C. R. Martin, Synth. Met., 1992, 47, 351-359.

3 J. J. M. Halls, C. A. Walsh, N. C. Greenham, E. A. Marseglia, R. H. Friend, S. C. Moratti and A. B. Holmes, Nature, 1995, 376, 498-500.

4 G. Yu, J. Gao, J. C. Hummelen, F. Wudl and A. J. Heeger, Science, 1995, 270, 1789-1791.

5 M. E. Aydin, F. Yakuphanoglu, J.-H. Eom and D.-H. Hwang, Phys. B, 2007, 387, 239-244.

6 N. O. Braga, D. G. S. M. Cavalcante, A. S. Gomes, E. Yoshihara, R. F. Bianchi and A. E. Job, J. Lumin., 2019, 210, 501-507.

7 A. Mhamdi, F. b. S. Sweii, H. Saidi, F. Saidi and A. Bouazizi, J. Mol. Struct., 2018, 1160, 33-37.

8 F. Semendy, G. Meissner and P. Wijewarnasuriya, Electrical and Optical Response Properties of MEH-PPV Semiconductor Polymer Schottky Diodes, 2011.

9 F. So, B. Krummacher, M. K. Mathai, D. Poplavskyy, S. A. Choulis and V.-E. Choong, J. Appl. Phys., 2007, 102, 91101.

10 C. Zhong, C. Duan, F. Huang, H. Wu and Y. Cao, Chem. Mater., 2011, 23, 326-340.

11 R. H. Friend, R. W. Gymer, A. B. Holmes, J. H. Burroughes, R. N. Marks, C. Taliani, D. D. C. Bradley, D. A. Dos Santos, J. L. Brédas, M. Lögdlund and W. R. Salaneck, Nature, 1999, 397, 121.

12 D. X. Yu, Int. J. Mol. Sci., 2011, 12, 1575-1594.

13 X. Gong, Org. Optoelectron., 2013, 277-336.

14 A. Menon, H. Dong, Z. I. Niazimbetova, L. J. Rothberg and M. E. Galvin, Chem. Mater., 2002, 14, 3668-3675.

15 L. Duan, L. Hou, T.-W. Lee, J. Qiao, D. Zhang, G. Dong, L. Wang and Y. Qiu, J. Mater. Chem., 2010, 20, 6392-6407.

16 B. Zhang, G. Tan, C.-S. Lam, B. Yao, C.-L. Ho, L. Liu, Z. Xie, W.-Y. Wong, J. Ding and L. Wang, Adv. Mater., 2012, 24, 1873-1877.

17 N. Aizawa, Y.-J. Pu, M. Watanabe, T. Chiba, K. Ideta, N. Toyota, M. Igarashi, Y. Suzuri, H. Sasabe and J. Kido, Nat. Commun., 2014, 5, 5756. 
18 N. J. Findlay, B. Breig, C. Forbes, A. R. Inigo, A. L. Kanibolotsky and P. J. Skabara, J. Mater. Chem. C, 2016, 4, 3774-3780.

19 C. Liu, Q. Fu, Y. Zou, C. Yang, D. Ma and J. Qin, Chem. Mater., 2014, 26, 3074-3083.

20 S. Ren, D. Zeng, H. Zhong, Y. Wang, S. Qian and Q. Fang, J. Phys. Chem. B, 2010, 114, 10374-10383.

21 J. A. Hur, S. Y. Bae, K. H. Kim, T. W. Lee, M. J. Cho and D. H. Choi, Org. Lett., 2011, 13, 1948-1951.

22 B. Yucel, N. Akcebe, M. Desde, E. Tekin, S. P. Mucur and P. Camurlu, Dyes Pigm., 2018, 156, 82-90.

23 D. Yokoyama, J. Mater. Chem., 2011, 21, 19187-19202.

24 M. Shibata, Y. Sakai and D. Yokoyama, J. Mater. Chem. C, 2015, 3, 11178-11191.

25 D. R. Widmer and B. J. Schwartz, Nat. Chem., 2018, 10, 910916.

26 R. M. Young and D. M. Neumark, Chem. Rev., 2012, 112, 5553-5577.

27 M. J. Blandamer and M. F. Fox, Chem. Rev., 1970, 70, 59-93. 28 R. A. Marcus, J. Chem. Phys., 1956, 24, 966-978.

29 R. A. Marcus and N. Sutin, Biochim. Biophys. Acta, Rev. Bioenerg., 1985, 811, 265-322.

30 E. Skuodis, O. Bezvikonnyi, A. Tomkeviciene, D. Volyniuk, V. Mimaite, A. Lazauskas, A. Bucinskas, R. Keruckiene, G. Sini and J. V. Grazulevicius, Org. Electron., 2018, 63, 29-40.

31 E. R. Barthel, I. B. Martini and B. J. Schwartz, J. Phys. Chem. $B, 2001,105,12230-12241$.

32 X. Gong, S. Wang, D. Moses, G. C. Bazan and A. J. Heeger, Adv. Mater., 2005, 17, 2053-2058.

33 S. Ho, S. Liu, Y. Chen and F. So, J. Photonics Energy, 2015, 5, 1-17.

34 P. Suppan, J. Photochem. Photobiol., A, 1990, 50, 293-330.

35 B. Bagchi, Int. Rev. Phys. Chem., 1987, 6, 1-33.

36 H. Wu, F. Huang, Y. Mo, W. Yang, D. Wang, J. Peng and Y. Cao, Adv. Mater., 2004, 16, 1826-1830.

37 A. Babaei, K. Rakstys, S. Guelen, V. Fallah Hamidabadi, M.-G. La-Placa, L. Martínez-Sarti, M. Sessolo, H. A. Joel, O. P. M. Gaudin, V. Schanen, M. K. Nazeeruddin and H. J. Bolink, RSC Adv., 2018, 8, 35719-35723.

38 J. You, S.-L. Lai, W. Liu, T.-W. Ng, P. Wang and C.-S. Lee, J. Mater. Chem., 2012, 22, 8922-8929.

39 H. Sasabe and J. Kido, Chem. Mater., 2011, 23, 621-630.

40 V. Peddie, J. Anderson, J. E. Harvey, G. J. Smith and A. Kay, J. Org. Chem., 2014, 79, 10153-10169.

41 C. Reichardt, Green Chem., 2005, 7, 339-351.

42 T. M. McCormick, C. R. Bridges, E. I. Carrera, P. M. DiCarmine, G. L. Gibson, J. Hollinger, L. M. Kozycz and D. S. Seferos, Macromolecules, 2013, 46, 3879-3886.

43 Y.-G. Ha, E.-A. You, B.-J. Kim and J.-H. Choi, Synth. Met., 2005, 153, 205-208.

44 D. Hewidy, A.-S. Gadallah and G. A. Fattah, J. Mol. Struct., 2017, 1130, 327-332.

45 T. Qin and A. Troisi, J. Am. Chem. Soc., 2013, 135, 1124711256.

46 Schrödinger release, 2016, vol. 2014, p. 3.
47 F. H. Allen, O. Kennard, D. G. Watson, L. Brammer, A. G. Orpen and R. Taylor, J. Chem. Soc., Perkin Trans. 2, 1987, S1-S19.

48 T. Steiner, Angew. Chem., Int. Ed., 2002, 41, 48-76.

49 O. V Dolomanov, L. J. Bourhis, R. J. Gildea, J. A. K. Howard and H. Puschmann, J. Appl. Crystallogr., 2009, 42, 339-341.

50 K. Molčanov, I. Sabljić and B. Kojić-Prodić, CrystEngComm, 2011, 13, 4211-4217.

51 C. F. Macrae, P. R. Edgington, P. McCabe, E. Pidcock, G. P. Shields, R. Taylor, M. Towler and J. van de Streek, J. Appl. Crystallogr., 2006, 39, 453-457.

52 J. C. de Mello, H. F. Wittmann and R. H. Friend, Adv. Mater., 1997, 9, 230-232.

53 Agilent Technologies, CrysAlisPro Data Collection and Processing Software for Agilent X-ray Diffractometers, Technol. UK Ltd, Yarnton, Oxford, UK, 2014.

54 G. M. Sheldrick, Acta Crystallogr., Sect. C: Struct. Chem., 2015, 71, 3-8.

55 G. M. Sheldrick, Acta Crystallogr., Sect. A: Found. Adv., 2015, 71, 3-8.

56 M. J. Frisch, G. W. Trucks, H. B. Schlegel, G. E. Scuseria, M. A. Robb, J. R. Cheeseman, G. Scalmani, V. Barone, B. Mennucci, G. A. Petersson, H. Nakatsuji, M. Caricato, X. Li, H. P. Hratchian, A. F. Izmaylov, J. Bloino, G. Zheng, J. L. Sonnenberg, M. Hada, M. Ehara, K. Toyota, R. Fukuda, J. Hasegawa, M. Ishida, T. Nakajima, Y. Honda, O. Kitao, H. Nakai, T. Vreven, J. A. Montgomery, J. E. Peralta, F. Ogliaro, M. Bearpark, J. J. Heyd, E. Brothers, K. N. Kudin, V. N. Staroverov, R. Kobayashi, J. Normand, K. Raghavachari, A. Rendell, J. C. Burant, S. S. Iyengar, J. Tomasi, M. Cossi, N. Rega, J. M. Millam, M. Klene, J. E. Knox, J. B. Cross, V. Bakken, C. Adamo, J. Jaramillo, R. Gomperts, R. E. Stratmann, O. Yazyev, A. J. Austin, R. Cammi, C. Pomelli, J. W. Ochterski, R. L. Martin, K. Morokuma, V. G. Zakrzewski, G. A. Voth, P. Salvador, J. J. Dannenberg, S. Dapprich, A. D. Daniels, O. Farkas, J. B. Foresman, J. V Ortiz, J. Cioslowski and D. J. Fox, Gaussian 09, Revis. B.01, Gaussian, Inc., Wallingford CT, 2009.

57 C. Adamo and V. Barone, J. Chem. Phys., 1999, 110, 61586170.

58 M. Ernzerhof and G. E. Scuseria, J. Chem. Phys., 1999, 110, 5029-5036.

59 J. P. Perdew, K. Burke and M. Ernzerhof, Phys. Rev. Lett., 1996, 77, 3865-3868.

60 J. Tomasi, B. Mennucci and R. Cammi, Chem. Rev., 2005, 105, 2999-3094.

61 S. Miertuš, E. Scrocco and J. Tomasi, Chem. Phys., 1981, 55, 117-129.

62 W. Kohn and L. J. Sham, Phys. Rev., 1965, 140, A1133-A1138. 63 Y. Zhao, N. E. Schultz and D. G. Truhlar, J. Chem. Theory Comput., 2006, 2, 364-382.

64 E. G. Hohenstein, S. T. Chill and C. D. Sherrill, J. Chem. Theory Comput., 2008, 4, 1996-2000.

65 S. Grimme, J. Antony, S. Ehrlich and H. Krieg, J. Chem. Phys., 2010, 132, 154104.

66 S. F. Boys and F. Bernardi, Mol. Phys., 1970, 19, 553-566. 
67 J. J. McKinnon, D. Jayatilaka and M. A. Spackman, Chem. Commun., 2007, 3814-3816.

68 J. J. McKinnon, M. A. Spackman and A. S. Mitchell, Acta Crystallogr., Sect. B: Struct. Sci., 2004, 60, 627-668.

69 J. J. McKinnon, A. S. Mitchell and M. A. Spackman, Chem.Eur. J., 1998, 4, 2136-2141.

70 M. A. Spackman and P. G. Byrom, Chem. Phys. Lett., 1997, 267, 215-220.
71 M. A. Spackman and J. J. McKinnon, CrystEngComm, 2002, 4, 378-392.

72 M. J. Turner, J. J. McKinnon, S. K. Wolff, D. J. Grimwood, P. R. Spackman, D. Jayatilaka and M. A. Spackman, CrystalExplorer17, 2017.

73 A. Gavezzotti, Mol. Phys., 2008, 106, 1473-1485. 